Author(s): Fiona King

Article title: Teacher professional development to support teacher professional learning: systemic factors from Irish case studies

Article no: RTDE 1161661

Enclosures: 1) Query sheet

2) Article proofs

Dear Author,

1. Please check these proofs carefully. It is the responsibility of the corresponding author to check these and approve or amend them. A second proof is not normally provided. Taylor \& Francis cannot be held responsible for uncorrected errors, even if introduced during the production process. Once your corrections have been added to the article, it will be considered ready for publication.

Please limit changes at this stage to the correction of errors. You should not make trivial changes, improve prose style, add new material, or delete existing material at this stage. You may be charged if your corrections are excessive (we would not expect corrections to exceed 30 changes).

For detailed guidance on how to check your proofs, please paste this address into a new browser window: http://journalauthors.tandf.co.uk/production/checkingproofs.asp

Your PDF proof file has been enabled so that you can comment on the proof directly using Adobe Acrobat. If you wish to do this, please save the file to your hard disk first. For further information on marking corrections using Acrobat, please paste this address into a new browser window: http:// journalauthors.tandf.co.uk/production/acrobat.asp

2. Please review the table of contributors below and confirm that the first and last names are structured correctly and that the authors are listed in the correct order of contribution. This check is to ensure that your name will appear correctly online and when the article is indexed.

\begin{tabular}{|c|c|c|c|c|}
\hline Sequence & Prefix & Given name(s) & Surname & Suffix \\
\hline 1 & & Fiona & King & \\
& & & & \\
\hline
\end{tabular}


Queries are marked in the margins of the proofs, and you can also click the hyperlinks below. Content changes made during copy-editing are shown as tracked changes. Inserted text is in red font and revisions have a red indicator $\curlywedge$. Changes can also be viewed using the list comments function. To correct the proofs, you should insert or delete text following the instructions below, but do not add comments to the existing tracked changes.

\section{AUTHOR QUERIES}

\section{General points:}

1. Permissions: You have warranted that you have secured the necessary written permission from the appropriate copyright owner for the reproduction of any text, illustration, or other material in your article. Please see http://journalauthors.tandf.co.uk/permissions/usingThirdPartyMaterial.asp.

2. Third-party content: If there is third-party content in your article, please check that the rightsholder details for re-use are shown correctly.

3. Affiliation: The corresponding author is responsible for ensuring that address and email details are correct for all the co-authors. Affiliations given in the article should be the affiliation at the time the research was conducted. Please see http://journalauthors.tandf.co.uk/preparation/ writing.asp.

4. Funding: Was your research for this article funded by a funding agency? If so, please insert 'This work was supported by <insert the name of the funding agency in full $>$ ', followed by the grant number in square brackets '[grant number $\mathrm{xxxx}$ ]'.

5. Supplemental data and underlying research materials: Do you wish to include the location of the underlying research materials (e.g. data, samples or models) for your article? If so, please insert this sentence before the reference section: 'The underlying research materials for this article can be accessed at $<$ full link $>/$ description of location [author to complete]'. If your article includes supplemental data, the link will also be provided in this paragraph. See $<$ http:// journalauthors.tandf.co.uk/preparation/multimedia.asp $>$ for further explanation of supplemental data and underlying research materials.

6. The CrossRef database (www.crossref.org/) has been used to validate the references. Changes resulting from mismatches are tracked in red font.

\begin{tabular}{|c|c|}
\hline AQ1 & Please check whether the affiliation has been set correctly. \\
\hline AQ2 & Please check whether the email address has been set correctly. \\
\hline AQ3 & Please check whether the abstract and keywords have been set correctly. \\
\hline AQ4 & $\begin{array}{l}\text { The reference 'King and Gilliland } 2009 \text { ' is cited in the text but is not listed in the } \\
\text { references list. Please either delete in-text citation or provide full reference details } \\
\text { following journal style } \\
\text { [http://www.tandf.co.uk/journals/authors/style/reference/tf_ChicagoAD.pdf]. }\end{array}$ \\
\hline AQ5 & $\begin{array}{l}\text { The reference citation for 'Opfer et al. } 2011 \mathrm{a} \text { ' has been changed to match the entry } \\
\text { in the references list. Please confirm that this is correct and provide revisions if } \\
\text { needed. }\end{array}$ \\
\hline AQ6 & $\begin{array}{l}\text { The reference 'King } 2011 \text { ' is cited in the text but is not listed in the references list. } \\
\text { Please either delete in-text citation or provide full reference details following journal } \\
\text { style } \\
\text { [http://www.tandf.co.uk/journals/authors/style/reference/tf_ChicagoAD.pdf]. }\end{array}$ \\
\hline
\end{tabular}




\begin{tabular}{|c|c|}
\hline AQ7 & $\begin{array}{l}\text { A quotation mark seems to be missing following 'PD does ... and led'. Please indi- } \\
\text { cate where it should be placed. }\end{array}$ \\
\hline AQ8 & $\begin{array}{l}\text { A quotation mark seems to be missing following 'While much ... learning'. Please } \\
\text { indicate where it should be placed. }\end{array}$ \\
\hline AQ9 & The disclosure statement has been inserted. Please correct if this is inaccurate. \\
\hline AQ10 & $\begin{array}{l}\text { The CrossRef database (www.crossref.org/) has been used to validate the references. } \\
\text { Mismatches between the original manuscript and CrossRef are tracked in red font. } \\
\text { Please provide a revision if the change is incorrect. Do not comment on correct } \\
\text { changes. }\end{array}$ \\
\hline AQ11 & $\begin{array}{l}\text { Please provide missing last page number for the 'Boardman et al. } 2005 \text { ' references } \\
\text { list entry. }\end{array}$ \\
\hline AQ12 & Please provide missing last page number for the 'Butler 1999' references list entry. \\
\hline AQ13 & Please provide missing city for the 'Cordingley et al. 2004' references list entry. \\
\hline AQ14 & $\begin{array}{l}\text { Please check whether the publication year has been set correctly for the 'Fullan } \\
\text { 1991" references list entry. }\end{array}$ \\
\hline AQ15 & $\begin{array}{l}\text { The reference 'Fullan et al. } 2005 \text { ' is listed in the references list but is not cited in } \\
\text { the text. Please either cite the reference or remove it from the references list. }\end{array}$ \\
\hline AQ16 & Please provide missing page numbers for the 'Grimmett 1995 ' references list entry. \\
\hline AQ17 & $\begin{array}{l}\text { Please provide missing city and publisher name for the 'Sahlberg 2012' references } \\
\text { list entry. }\end{array}$ \\
\hline AQ18 & Please provide missing page numbers for the 'Sytsma 2006' references list entry. \\
\hline
\end{tabular}




\section{How to make corrections to your proofs using Adobe Acrobat/Reader}

Taylor \& Francis offers you a choice of options to help you make corrections to your proofs. Your PDF proof file has been enabled so that you can mark up the proof directly using Adobe Acrobat/ Reader. This is the simplest and best way for you to ensure that your corrections will be incorporated. If you wish to do this, please follow these instructions:

1. Save the file to your hard disk.

2. Check which version of Adobe Acrobat/Reader you have on your computer. You can do this by clicking on the "Help" tab, and then "About".

If Adobe Reader is not installed, you can get the latest version free from http:/get.adobe.com/ reader/.

3. If you have Adobe Acrobat/Reader 10 or a later version, click on the "Comment" link at the right-hand side to view the Comments pane.

4. You can then select any text and mark it up for deletion or replacement, or insert new text as needed. Please note that these will clearly be displayed in the Comments pane and secondary annotation is not needed to draw attention to your corrections. If you need to include new sections of text, it is also possible to add a comment to the proofs. To do this, use the Sticky Note tool in the task bar. Please also see our FAQs here: http://journalauthors.tandf.co.uk/production/ index.asp.

5. Make sure that you save the file when you close the document before uploading it to CATS using the "Upload File" button on the online correction form. If you have more than one file, please zip them together and then upload the zip file.

If you prefer, you can make your corrections using the CATS online correction form.

\section{Troubleshooting}

Acrobat help: http://helpx.adobe.com/acrobat.html

Reader help: http://helpx.adobe.com/reader.html

Please note that full user guides for earlier versions of these programs are available from the Adobe Help pages by clicking on the link "Previous versions" under the "Help and tutorials" heading from the relevant link above. Commenting functionality is available from Adobe Reader 8.0 onwards and from Adobe Acrobat 7.0 onwards.

Firefox users: Firefox's inbuilt PDF Viewer is set to the default; please see the following for instructions on how to use this and download the PDF to your hard drive: http://support.mozilla.org/ en-US/kb/view-pdf-files-firefox-without-downloading-them\#w_using-a-pdf-reader-plugin 


\title{
Teacher professional development to support teacher professional learning: systemic factors from Irish case studies

\author{
Fiona King*
}

\author{
School of Inclusive and Special Education, DCU Institute of Education, Dublin, Ireland
}

(Received 1 January 2014; final version received 1 June 2015)

Teacher professional learning is widely accepted as a mediating factor for enhancing student outcomes. While many teachers across the world engage in professional development (PD) to enhance their professional learning, what is less evident is how to support that learning to result in change following teacher PD. Acknowledging that not all teacher PD needs to result in new practices and change this paper focuses on a transformative model of PD, focused on implementing and sustaining change. This paper offers evidence of successful implementation and sustainability of practices by drawing from in-depth semi-structured interviews with teachers and principals in five Irish case study schools. It reports on the Systemic/Factors to support implementation and sustainability of change: Support, Initiative design and Impact and Teacher Agency. Implications are drawn for bridging the gap between knowledge and practice or teacher PD and change within schools.

Keywords: CPD; professional development; change; sustainability; professional learning

\section{Introduction and rationale}

Despite a burgeoning international literature advocating teacher professional learning as an essential mediating factor for enhancing student outcomes, the knowledge practice gap (Kennedy 2014) or implementation and sustainability of change in schools remains somewhat elusive. Teacher professional learning has been defined as the growth of teacher expertise leading to a change in practices to result in improved student outcomes (New South Wales (NSW) Institute of Teachers 2007). However teacher professional learning is arguably a complex system rather than a single event of changing practices (Opfer and Pedder 2011b). This complex system involves systems within systems made up of individual teachers, interactions between teachers, school-level systems and interactions between teachers and school-level systems (Opfer and Pedder 2011b). In this context teacher professional learning is seen as a process of learning leading to a growth of teacher expertise. This process is arguably situated and influenced by a myriad of situational factors which can support or impede a change in practices, which is defined as a change in knowledge, understanding, skills, behaviours, attitudes, values or beliefs (Evans 2010). Therefore understanding teacher professional learning through theorising

*Email: flona.king@sped.deu.ie 
same (Kennedy 2014) may help narrow the knowledge practice gap between professional learning and changes in practices.

Significant to teacher professional learning is the contested concept of teacher professional development (PD) which can be viewed conceptually at the "macrolevel concerns or the micro-level realities' (Guskey 1991, 240) each having their own agenda based on identified needs at a given time. Arguably both agendas are aligned with the view of the New South Wales (NSW) Institute of Teachers, who describe PD as the 'processes, activities and experiences that provide opportunities to extend teacher professional learning' $(2007,3)$. However some view teacher PD as accumulation of knowledge through in-service, training or courses while others argue that knowledge accumulation does not necessarily result in deep professional learning which is needed to change practices (NCCA 2008). This is reflected in what Bubb, Earley, and Hempel-Jorgensen (2008) observed in their study of staff development outcomes which showed that some teachers feel no responsibility to change practices as a result of PD. Equally while teachers may value certain practices they don't necessarily implement them (Opfer and Pedder 2011a). It is important however to acknowledge that the purposes of PD may vary along a continuum from transmission of knowledge and skills at one end to transformative practice at the other end where teachers are encouraged to work collaboratively in a constructivist manner to change their practices to better meet the needs of their students in their context (Kennedy 2005, 2014). This paper aims to explore the link between a model of teacher PD that focuses on transformative practice and the implementation of change to understand the factors necessary for the growth of teacher expertise (professional learning). It draws upon a qualitative study which demonstrated how a transformative model of PD led to the implementation and sustainability of change resulting in improved student outcomes.

\section{The PD initiative}

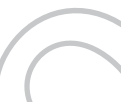

The PD initiative in this study was undertaken in five urban, primary, disadvantaged schools in the Republic of Ireland (ROI) and involved teachers engaging in a collaborative PD literacy initiative. The initiative was first implemented in 2007-08 where an initial study focused on the impact of the literacy intervention on students' outcomes. Nineteen schools responded to an advertisement in the Irish National Teachers Organisation (INTO) (teacher union) magazine inviting schools to engage in a literacy initiative. Five schools who met the criteria (urban, disadvantaged status, class grouping not participating in another reading initiative) were chosen to receive funding and support from the INTO. This funding of the PD initiative consisted of materials, the input of a facilitator, substitute cover for teachers to attend a PD day, two school visits and email and telephone support. The initiative involved students in 3rd class (average age 9) and required a special educational needs (SEN) teacher and a classroom teacher to work collaboratively within the mainstream classroom to implement Peer Tutoring (Topping 1988; Butler 1999) for literacy over a ten week period. This included two weeks of training the students to work in pairs on the literacy initiative and eight weeks of implementation of the literacy initiative for thirty minutes a day, four days a week. Peer Tutoring in this study involved students reading in mixed ability pairs in the role of tutor and tutee with the aim of improving their reading accuracy and fluency. 
The SEN teacher, class teacher and principal of each of the five schools (A-E) were invited to attend the PD day which focused both on the procedural aspect of the literacy initiative and the conceptual underpinnings of the peer tutoring model to be undertaken. See Appendix A for a typical 30 min session of the literacy initiative. Individual teacher roles throughout the session were explored in detail. This was important given that the teachers were not used to working collaboratively within the same classroom. Teachers would take responsibility for half of the pairings each where they would listen to the pupils read and support them in the learning of new vocabulary and sight words. They would choose to alternate this or remain with the same pairings according to what they felt best met their individual needs.

The assessment to be used for individual pre and post testing of pupils' literacy skills was also introduced and explored in detail as the teachers were carrying out these assessments. The SEN teacher, class teacher and principal from four (B-E) of the five schools attended the day. The SEN teacher, class teacher and literacy co-ordinator attended from the fifth school (A). The follow up support for the teach-

20 ers came in the form of two school visits over the duration of the eight week implementation of the literacy initiative. In each of the schools this involved observing the peer tutoring model in practice and supporting teachers with any questions or queries they had regarding the model. In some cases suggestions were offered following the observation, for example, only allowing pupils to change their reading books at the end of the 30 min session to ensure that they were getting the maximum time for reading.

Findings appeared to show an overall average improvement of 12.7 months in reading accuracy for pupils $(n=116)$, high levels of pupil engagement and enjoyment along with teachers' willingness to sustain the practice beyond the initial implementation period (King and Gilliland 2009). A later study, from which this paper draws its findings, was carried out in 2010 -11 to assess if and how the initiative was being used in the same schools three years on. The rationale for this research emerged from the literature, which reported little evidence of sustainability of practices over a longer period of time (Baker et al. 2004; Priestley et al. 2011). This paper therefore aims to explore the complex concept of teacher PD within the concept of teacher professional learning and factors that support implementation and sustainability of change. It will also explore how these factors can be considered when planning and evaluating the impact of teacher PD to enhance the link between teacher PD and implementation and sustainability of change. It is hoped that these factors may also enhance our understanding of teacher professional learning to narrow the knowledge practice gap.

\section{Teacher PD}

Teacher professional learning has been directly linked with improved student outcomes (Hattie 2003). Consequently many countries continue to invest significant amounts of money in teacher PD (processes, activities and experiences that provide opportunities) to enhance teacher professional learning. Despite this, little evidence exists as to whether and how teachers implement and sustain new practices (Baker et al. 2004; Priestley et al. 2011) and thus narrow the knowledge practice gap. Perhaps this is related to how teacher PD is conceptualised with many viewing it as courses, training or in-service type activities instead of adopting a broader view such as that postulated by Bubb and Earley (2008) and the NSW Institute of Teachers 
(2007) where PD is not defined by activities, courses or experiences but rather as an outcome from these courses, activities or reflections on day-to-day experiences in the classroom. This conceptualisation of PD places it as a 'third-order activity' (Cordingley et al. 2004, 14) where the emphasis is on the growth of teacher professional learning to enhance student outcomes.

Given the importance attached to PD it is not surprising that it is mandatory in many countries across the world. Noteworthy is the fact that ongoing PD is currently not a requirement for registration with the Teaching Council of Ireland (TCI). However, teacher PD is seen as 'a right and a responsibility' (TCI 2011, 19) with teachers having a right to access $\mathrm{PD}$ and a responsibility to engage with $\mathrm{PD}$. Interestingly the TCI is currently involved in a consultation process with teachers regarding continuing PD and how this should be conceptualised and realised. Despite being mandatory in many jurisdictions arguably there is still a problem with implementation and sustainability of new practices. As far back as 1988, Cuban observed that 'Innovation after innovation has been introduced into school after school, but the overwhelming number of them disappear without a fingerprint' $(1988,86)$. By 1999, the problem still permeated education: 'Innovations are introduced before previous ones are adequately implemented' (Fullan 1999, 27). Twelve years later Sahlberg (2012) claimed that '.. the real problem ... in education is we tend to develop innovation after innovation without really solving the problem of implementation'. This is disconcerting given that a critical component for school improvement is sustainability of new practices, and yet very little evidence is available on whether schools sustain and embed such changes (Baker et al. 2004; King 2014). Much focus is on short-term impact, with long-term impact often ignored (Ofsted 2006; Timperley 2008). To render teachers' PD more effective for supporting teachers' professional learning, a deeper understanding of how practices are enacted in schools and factors that help or hinder such changes is necessary (Wermke 2010).

Reconceptualising PD as a third-order activity (Cordingley et al. 2004) without understanding the conditions to support such changes may not result in change. It is important to understand how the link between teacher PD, changes in teacher practices and student outcomes can be supported (King 2013). General orthodoxy supports the following factors as being conducive to implementation and sustainability of new practices: teachers engaging in high quality PD (Desimone et al. 2002); acknowledging individual teachers in the change process and school context (Kervin 2007), deep learning and professional learning communities (Bolam et al. 2005) and school culture (Norris 2004).

Desimone et al. (2002) categorise high quality PD into the structure of the PD and the core of the PD. The structure encompasses the organisation of the activity such as the duration of the activity, type of activity (such as network, mentoring, research, workshop ...) and collective participation. The emphasis on collective participation echoes Fullan (2001) and Kennedy's (2011) view on the importance of collaborative PD for enhancing student outcomes. However the gap between theory and practice relating to collaborative PD may need to be explored, especially in the Irish context where individual practice still reigns (O'Sullivan 2011; Eivers and Clerkin 2013). Meanwhile, Desimone et al. (2002) describe the core of PD as the characteristics of the actual PD activity or experience and these are explored under the headings of active learning (for example analysis, of teaching and learning through peer observation), coherence (how it aligns with teachers', school and department aims) and content (subject matter content and how students learn that content). 
Kervin (2007) has contributed to this debate in more recent times. She highlights the importance of the school context and the centrality of the individual teacher in the change process, reflecting perhaps Opfer and Pedder's (2011b) view of teacher learning as systems within systems. This paper will now explore these two concepts in the context of how they relate to implementation and sustainability of practices.

Kervin (2007) argues that PD needs to be aligned with individual teachers' needs, beliefs, practices and levels of experience or expertise. Arguably what is left somewhat unproblematized is whether changes in beliefs or practices happen first. According to Hargreaves and Fullan (1992) changes at a behavioural level are pre10 ceded by changes in understanding and beliefs about how students learn. This however stands in contradistinction to others who argue that teachers can change their practices first (Guskey 2002; Bolt 2007) followed by improved student learning and lastly teacher attitudes and beliefs. However, presenting change in a linear fashion has been criticised by others who argue that change is not a linear process, rather a 15 reciprocal interplay between changes in beliefs, practices and students with no definitive starting place (Opfer, Pedder, and Lavicza 2010). Compounding the issue of the order of teacher change is the argument that teachers' values and beliefs may often be greater than their practices (Opfer and Pedder 2011a), perhaps due to other influencing factors such as the culture and context of the school and individual tea-

20 cher characteristics. This once again highlights the importance of the school context in relation to teacher engagement with $\mathrm{PD}$.

Issues may arise within the school context where a mismatch exists between teachers' individual PD needs and those of the school or department. This may be more evident in a climate of standardisation and accountability where changes 25 within schools are often imposed by principals or PD co-ordinators (Bolam et al. $2005)$ in a top-down fashion through performance management. Effectively, this renders teachers as 'technicians carrying out someone else's policy' (Priestley et al. 2011, 269) rather than being active, creative, self-directed participants in their own professional learning. 'The most important skill of all for both children and adults is 30 learning how to learn; the process of self-directed inquiry' (Knowles 1980, 41). Therefore effective PD needs to facilitate a personalised approach (Bubb and Earley 2008) allowing teachers some autonomy to pursue individual qualifications or training and to be at the centre of identifying, planning, actualising, and evaluating their own/earning, a process known as andragogy, which is one of the key principles in 35 understanding and engaging in adult learning (Knowles 1980). Arguably this may be achieyed within a culture of standardisation and performativity through mobilising the teaching profession to find 'space' (Bell and Bolam 2010) to adapt national strategy in a way that is consonant with their own beliefs and contex (Dng 2011). Teachers can be supported in this by the culture in schools, such as ethos, the 40 way they do things and their state of readiness for change, which it is argued is often influenced by the nature and quality of leadership (NCCA 2010).

PD does not just happen - it has to be managed and led' (Earley and Bubb, 204, 80) or led and supported (NCCA 2010) perhaps through the use of an 'implementation bridge' (Hall and Hord 2006, 10) to help teachers gradually engage with new practices without throwing away what is working with existing practices. While the TCI in Ireland acknowledges the principal's role in PD ((TCI) Teaching Council of Ireland 2011) it is important to recognise that approaches to leadership vary. Some principals may adopt a managerial approach to PD where it is mandated and prescribed arguably resulting in what Kennedy (2005) calls transmission models of PD 
with teachers as technicians carrying out someone else's agenda. Others however, may choose a more collaborative approach focused on winning teachers hearts and minds and a desire for collaborative school improvement. This form of leadership is often associated with transformative models of PD where teachers are supported to work collaboratively in a constructivist manner to change their practices to meet the needs of their students in their contexts (Kennedy 2005). Supporting teachers to work collaboratively, to share their expertise and to take risks together (Stoll and Fink 1996; Sergiovanni 2005) may lead to greater capacities for change and school improvement (Bryk and Schneider 2002). However if principals mandate collaborative practices in a managerialist approach, 'contrived collegiality' (Hargreaves 1994, 247) may result, leading to a negative impact on sustainability of collaborative practices.

Sustaining change can be difficult (NCCA 2010) for a number of reasons, for example, high rates of staff turnover and the expertise moving with the staff or increasing pressures or demands on teachers' time for implementation of new programmes. Nevertheless, certain factors have been identified in the literature as supporting sustainability of practices over time; deep learning, professional learning communities and school culture.

Bolam et al. (2005) argue that deep learning is required for sustaining change, that is, teachers having a conceptual understanding of practices and their use; knowledge of the curriculum or subject area, knowledge of pedagogy and pedagogic content knowledge. Deep learning could enable teachers to move from curriculum transmission to curriculum development (teachers supplementing and adapting curriculum to local settings and needs) and curriculum making (teachers constructing curriculum having assessed individual students' needs) (Shawer 2010).

However teachers may need support to engage with practices at this deeper conceptual level. Whether or not this support is available in a culture of increasing performativity and 'quick fixes' is questionable. Arguably not affording teachers the support to engage with practices at a conceptual level compounds the difficulty of sustainability of practices. This support may be in the form of developing collaborative cultures, such as professional learning communities (PLCs), to enhance the overall capacity of the school.

For the purpose of this article PLCs will be discussed in terms of how they relate to sustainability of practices in the context of a school. Bolam et al. (2005) outline eight characteristics of effective PLCs; shared values and vision; collective responsibility for students' learning; collaboration focused on learning; individual and collective professional learning; reflective professional enquiry; openness, networks and partnerships; inclusive membership; and mutual trust, respect and support. Further analysis and synthesis of effective PLCs within the literature reveal some challenges to the development of PLCs. Fallon and Barnett (2009) in their Canadian qualitative study highlighted teachers' impressions of PLCs as something that is based on authoritarianism and hostile to innovation and creativity. This stands in contradistinction to the aspirations of others who argue that the central precepts underlying the development of PLCs include teachers engaging collaboratively on an agreed topic decided by the group with agreed collective responsibility for teaching and learning and equality of participation and activity (Sytsma 2006; Seed 2008). O'Sullivan (2011) contends that these aspirations can be achieved with an emphasis on shared leadership and supportive conditions for the development of PLCs. Therefore 
the culture in which PLCs are promoted may be highly influential in their ability to enable schools to embed changes.

School culture encompasses the way things are done in a school (Norris 2004) or how schools operate (Evans 2008) and it is reflected in the underlying values and beliefs posited by a school. Culture can be created by teachers and leaders and can change as teachers and leaders change (Stoll and Fink 1996). A school culture can support teachers to focus on a new practice through which they may develop new collaborative relationships and trust which may in turn unite them in their issues (Earley and Bubb 2004). Through such collaborative activities PLCs may develop (Hayton and Spillane 2008; Fallon and Barnett 2009) and provide a mechanism for diffusion of practices within the school context.

Despite a burgeoning literature that extols the virtues of deep learning, PLCs and school culture for sustainability of practices it is accepted that underpinning all of this is the importance of individual teachers as change agents, acting in intentional ways to 'shape their own responses to problematic situations' (Fallon and Barnett $2009,12)$ in a process known as human agency Acknowledging teacher agency as part of teacher professional learning (Billett 2009) is important for school 20 improvement.

Teacher professional learning can be seen as a potent means of facilitating teacher engagement with change for school improvement. While much focus has been on providing high quality PD to enhance teachers' learning what is less clear is how to support teachers to engage with and sustain new practices over time and how to understand teacher professional learning and processes of learning. Arguably high quality PD will result in changes in teacher practices and improved student outcomes. However the link between high quality PD and new practices being implemented or sustained is not automatic. This paper draws upon a study which explored teachers' perceptions of implementing and sustaining a literacy practice over a three year period. It also highlights the key factors that shaped this long-term development and sustainability of teachers' professional practice and learning.

\section{Methodology}

The epistemological and ontological stances that underpinned this study are subjective; it is believed that knowledge is constructed by individuals' perceptions or 35 beliefs while reality of the social world is constructed by the participants engaged within it. Given that this study sought to explore teachers' perceptions of the change process over time, a qualitative research methodology, consonant with the philosophical approach, was employed. Sampling was purposive with semi-structured interviews carried out with individual participants (20 in total) engaged in the PD initiative in each of the five schools with a view to understanding how individual teachers experienced the implementation and sustainability of the practice and what supported them or hindered them in the change process. On returning to the schools three years on from the initial study some teachers had retired or moved on. Given the flexibility of case study research it was possible to interview other people in the 45 schools who had subsequently engaged with the initiative as the focus was on the impact of the PD initiative on their practice and the factors that supported or hindered the implementation and sustainability of the practice. This article represents part of a wider study evaluating the impact of teacher PD on developing and sustaining teachers' professional learning and the factors that helped or hindered this 
learning. Data collection for the wider study was guided by a conceptual framework (Miles and Huberman 1994) which emerged from the literature for exploring the impact of PD. While a previous article focused on the development process of the framework and its evaluation (King 2014) the focus in this article is on understanding the factors that supported the link between knowledge and practice or PD and implementation and sustainability of changes. The section of the conceptual framework used to guide the design and analysis of the findings are represented in Figure 1 below and in the research questions outlined below.

\section{Research questions}

(1) What were the key factors that shaped the changes in teachers' professional practice and learning during the ten-week period (the initial implementation following PD)?

(a) What factors had a positive impact on the implementation of the initiative?

(b) What factors had a negative impact on the implementation of the initiative?

(2) What were the key factors that shaped the long-term development and sustainability of teachers' professional practice and learning?

(a) What factors had a positive impact on the long-term development and sustainability of teachers professional practice and learning?

(b) What factors had a negative impact on the long-term development and sustainability of teachers' professional practice and learning?

An inductive approach to data analysis was undertaken, that is, one where the codes or categories are not predetermined (Bryman 2004; Gray 2004), thus reflecting further alignment with a subjective epistemology and an interpretivist understanding of participants' meanings. Descriptive codes emerged following round one of analysis (Organisation support- OS. How school helps/hinders (OS - Hel/Hin) and these were later expanded into sub-themes in round two and three of coding to answer the above research questions. Sample of codes include: Positive- Leadership - Alignment;

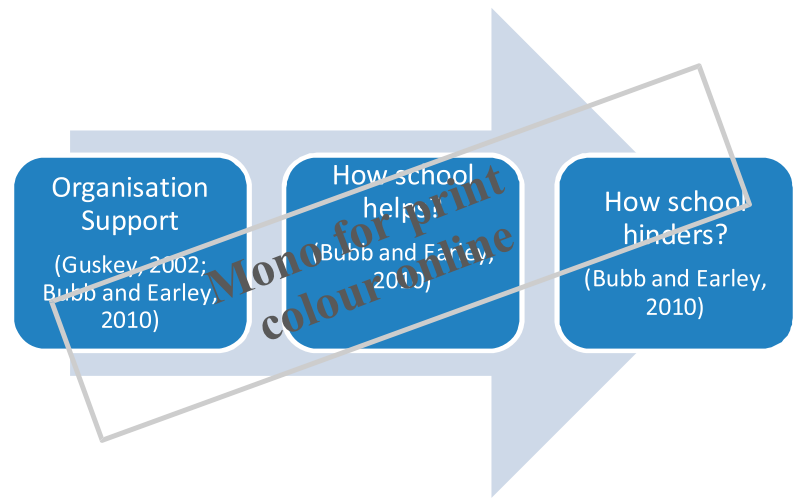

Figure 1. Conceptual framework. 
Positive - Leadership - Creating Organisational Capacity. To provide an audit trail of the data all codes were given a clear definition, for example the definition for Positive- Leadership - Alignment was Reported alignment of principals' and teachers'values, i.e., principals and teachers valued the literacy aspect and therefore principals opted their schools into the initiative. The findings which emerged from the data in this way are now presented below.

\section{Findings}

Findings presented here draw from a wider study that focused on exploring the impact of PD on teachers' practices. This study revealed a large number of teachers, representing four out of the five schools, sustained new practices over time, albeit in

15 different forms. Teachers responded in different ways to facilitate the implementation and sustainability of change to better meet the needs of their students in their context. The focus of this paper is to identify and understand the factors that appeared to help bridge the knowledge practice gap and thus the implementation and sustainability of change through exploring teachers' perceptions of the process 20 within the context of the study. It is hoped that knowledge of these factors will add to the current understanding of supporting teachers' professional learning in a transformative way (Kennedy 2014).

The conceptual framework used to guide this study explored the organisation support involved in supporting teachers' professional learning. Organisational sup-

25 port was characterised by a number of possible formats of support: a change agent; leadership; policies; resources or; time for sharing and reflection. However findings from the data clearly revealed consistencies within and across four case study schools regarding supportive features of implementation and sustainability of change. Three consistent features of teachers' professional learning that supported 30 such changes are encapsulated under the heading Systemic Factors; Support, Initiative Design and Impact and Teacher Agency. These features which clearly represent more than organisation support are referred to as 'Systemic Factors' (King 2014) and thus help provide detail about PD processes (Cordingley, Bell, and Thomason 2008). While these have been acknowledged briefly in a previous paper which 35 explored the design process of a PD evaluation framework (King 2014), this paper explores the meaning of these Systemic Factors in detail with the aim of supporting others in bridging the gap between teacher PD, teacher professional learning that results in the implementation and sustainability of change.

\section{Systemic factors}

40 Support for teachers in this study was in the form of support from leadership, an advocate or change agent and professional learning communities (PLCs). Leadership made a significant contribution to the implementation and sustainability of practices in the schools. Three key features emerged of how principals supported teachers' engagement with and sustainability of new practices: alignment between teachers' 45 and principals' values; creating organisational capacity for change and; empowering teachers to create collaborative learning cultures and PLCs (King 2011). See Figure 2. These will now be explored in the context of the findings.

In four out of the five schools where the practice was sustained a teacher was responsible for bringing the PD initiative to the attention of the principal. Teachers' 


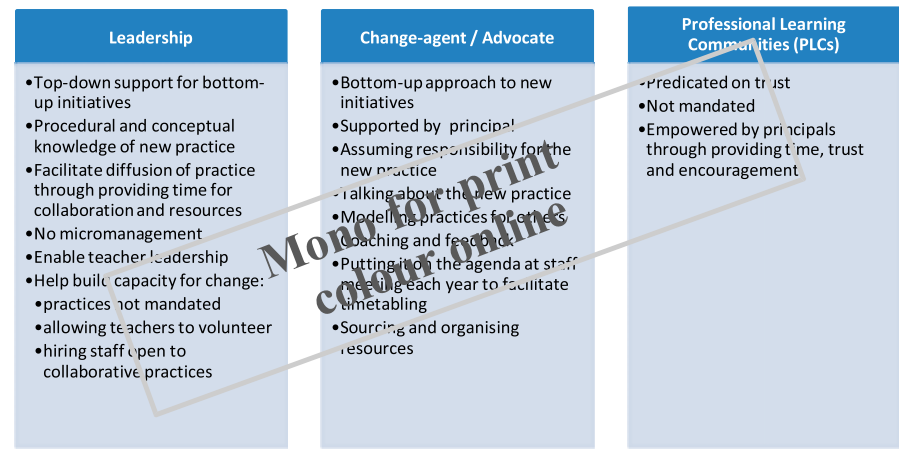

Figure 2. Support.

desire to engage with the new initiative centred largely on wishing to improve the literacy outcomes of their students. This aligned with principals' values, thus demonstrating strong supportive preconditions for capacity building for change (Bjorkman and Olofsson 2009), resulting in principals supporting their teachers by opting them into the initiative. Two of the principals also wanted to introduce collaborative teaching practices in their schools and embraced this opportunity to do so as they felt it would be best not to mandate collaborative practices in a top-down fashion (King 2011).

Having opted their teachers into the initiative, principals then created organisational capacity for change by allowing teachers to volunteer to work collaboratively on the literacy initiative. Principals from the four schools demonstrated to teachers that they valued the initiative by attending the initial PD day which centred on the procedural and conceptual aspects of the literacy initiative. While these principals had been involved in the early stages of the implementation of the practice, they continued to support it without micromanaging it. As long as their teachers valued the practice for supporting their students' learning, principals were happy to support it in terms of securing time for teachers to collaboratively plan and reflect, providing resources and timetabling teachers each year to allow for the collaborative teaching of the initiative. Support and trust were central components of principals creating organisational capacity for change despite other pressures and constraints.

Compounding the issue of sustainability of practices was the high rate of staff turnover. However principals supported teachers by enabling them to become leaders themselves through modelling practices for other teachers willing to engage with the practice, providing time for peer observation and collaborative planning and evaluation of the practice. In essence they empowered teachers to create PLCs focused on the teaching and learning of their students to help sustain practices (King 2011). What emerged from this PD initiative was much more than sustainability of the practice, teachers developed collaborative cultures such as PLCs and these were reported as being critical in the sustainability of the practice and its diffusion to other teachers. Allowing teachers to volunteer for the collaborative practice as distinct from mandating it was cited by all teachers as instrumental in their engagement and sustainability of the practice over time. Interestingly two principals also remarked that when hiring new teachers they looked for teachers who were open to collaborative teaching practices as this would facilitate sustainability of the 


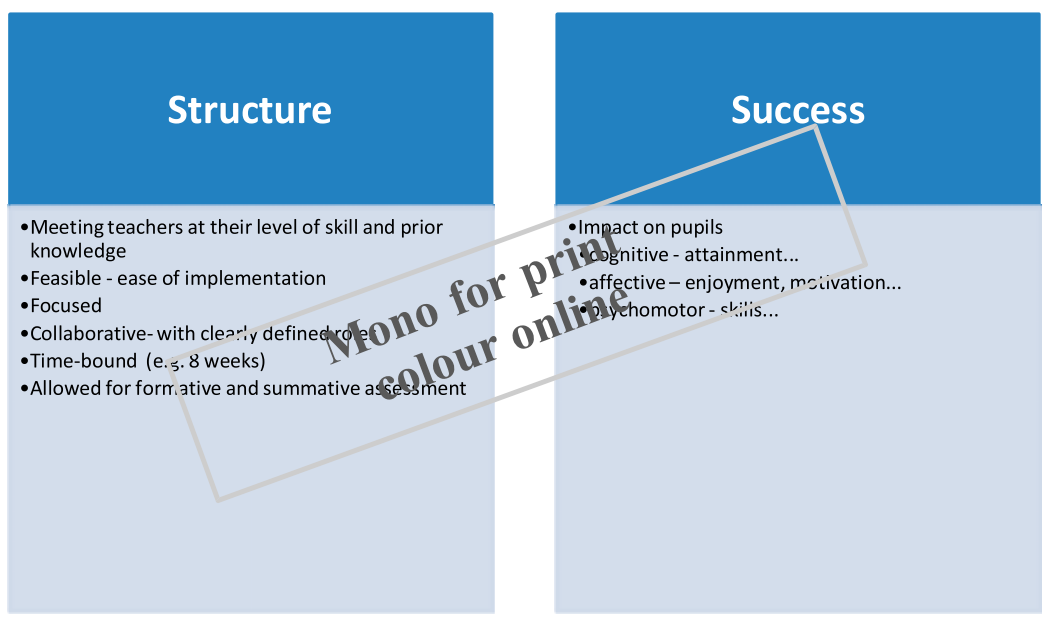

Figure 3. Initiative design and impact.

collaborative practice. The practice was diffused to many other teachers in the schools over the three year period with one school having all of their teachers participating in the initiative. This kind of support from principals has been termed agentic leadership (King 2013) where principals or leadership from above empowered an organic form of leadership from below where teachers regardless of their role identified an initiative to support their students' needs and looked for top-down support (King 2013).

The teachers who brought the initiative to the attention of their peers and the principal acted as change-agents or an advocate for the practice and they were supported by the principals. In all cases this teacher or change-agent took responsibility for the initiative as they valued it and wanted it to be sustained. They were responsi-

15 ble for putting it on the agenda at staff meetings each year so that it could be timetabled and resources could be ordered if necessary. They modelled practices for other teachers and provided coaching and feedback (Joyce and Showers 1995). All of this was done in a culture of collegiality where teachers spoke about the practice and encouraged others to get involved. Overall the support from leadership was the

20 vehicle through which the change agent and development of PLCs were enabled (King 2011). However support alone was not enough to ensure implementation and sustainability of the practices. Another contributing factor was that of the initiative design and impact. See Figure 3.

\section{Initiative design and impact}

25 The design of the PD literacy initiative undertaken by the participants was in itself a highly influential factor in its implementation and sustainability. All participants commented on the structure of the initiative, albeit with slightly different connotations of the concept of structure. 'Administratively it's relatively easy to run' commented one principal while another principal asserted: 


\section{$12 \quad$ F. King}

it's not as difficult to run as some other programmes.... Some things are just so complicated ... it is hard work to even try and get people to have the time to look at them properly ... they just give up a little bit on it and try to go for other programmes like this that are more tangible and more easy to manage.

This reflects what many teachers mentioned about the ease with which the new literacy practice in this study could be implemented. Teachers described the initiative as 'feasible', 'focused', 'very structured', 'very workable' and having a 'clear framework'. This may be reflective of the importance of meeting teachers at their levels of skill and prior knowledge (Kervin 2007) to ensure that they feel they have the capacity for the practice (Priestley et al. 2011). This in turn may help enhance teacher confidence, efficacy and morale, all of which are essential for teacher engagement with new initiatives (Bubb and Earley 2008).

A number of teachers commented on the fact that it was a time bound initiative (over ten weeks), was an influential factor in their decision to engage with the initiative and sustain the practice in subsequent years. Perhaps it reduced teachers' fear of committing to long-term change, thus echoing Hall and Hord's $(2006,10)$ suggestion for principals to employ an 'implementation bridge' to help teachers gradually engage with new practices without throwing away what is working with existing practices. There may also be less risk with a short-term initiative so perhaps this was an influential feature for principals too. This short intensive approach to PD initiatives may be inspiring for others who are aiming to effect change in their schools, because while the initiative itself was time bound, the effects seeped through to other aspects of teachers' practice on a longer-term basis.

Another finding related to the structure of the initiative centred on it being a collaborative initiative requiring teachers to work collaboratively in a mainstream classroom to support students' literacy. While this appealed to two of the principals who wanted to initiate collaborative practices in their schools, none of the teachers cited this as a contributing factor for engagement with the practice. Interestingly a number of teachers however claimed that the collaborative aspect of the practice was instrumental in its sustainability as teachers enjoyed working with each other and learning from each other. One teacher reported:

That [team teaching] was new and ... I really liked the fact that there were other people, especially other skilled people ... They had a wisdom and knowledge and I was able to learn from them as well. So I found it, as a new teacher, very very beneficial because I was able to learn lots from experienced people.

This perhaps echoes what Desimone et al. (2002) postulated in relation to the structure of high quality PD, that is, collective participation as distinct from PD that focuses on individual teachers. The structure of the initiative also resulted in both teachers in the classroom having clearly defined roles, therefore eliminating their fears of working collaboratively together within the mainstream classroom.

It was so structured and it allowed for ease of planning ... for team teaching ... there was no fear ... and everyone seems to know their role in a clearer way. (Class teacher)

What eventuated from this initiative was much more than sustainability of the literacy practice; it led to the development of other collaborative practices within the schools and the development of collective responsibility and ownership for students' learning and school improvement (Seed 2008; King 2011). 
Other teachers liked the fact that the structure of the practice allowed for formative and summative assessment thus providing them with a mechanism for knowing if the practice was impacting on students' learning. The success of the literacy initiative on students' outcomes was specified by many teachers as being an important factor in its sustainability over time and also in securing new teachers to the practice. This is reflected in one teacher's comments: 'I heard the results from teachers who had done it before were very good and positive towards improving literacy'. These comments also show how teachers value the opinion of other teachers in terms of what works for their students (Boardman et al. 2005; Carter and Whel10 dall 2008) and this contributed to some teachers subsequently engaging with the initiative. Interestingly teachers valued affective and psychomotor outcomes as well as cognitive outcomes and teachers employed their own professional judgement in deciding if the practice was successful and therefore worth sustaining. Despite an emerging managerialism which emphasises student outcomes and cost-effectiveness 15 (Gewirtz and Ball 2000), the findings suggest that teachers are still motivated by pupils' affective outcomes: practices that they perceive their pupils enjoy and find motivating and interesting (Boardman et al. 2005). Given that student motivation is an important aspect for enhanced student learning it is important that affective outcomes are valued.

20 The design and structure of the literacy initiative, together with its success for students were important factors in its 'legacy' (King 2012). It is hoped that, while the concept of structure may be somewhat reflective of that identified by Garet et al. (2001) and Desimone et al. (2002) as essential for high quality PD, the various components of initiative design and impact outlined here may contribute somewhat fur-

25 ther to the debate on high quality PD. Another important factor that supported teachers' engagement with and sustainability of the literacy initiative in this study, which does not appear to feature in the work of Garet et al. (2001) and Desimone et al. (2002) on factors of high quality PD, is the role of teacher agency. See Figure 4.

30 Teacher agency: Acknowledging and valuing the pivotal role of teachers in the change process is necessary for school improvement (NCCA 2010). Arguably teachers are the gatekeepers of change or the change-agents in the PD process (Guskey 2002; Bubb and Earley 2010). Findings in this study indicate that teachers' openness and willingness to engage with and sustain the practice was significant in its

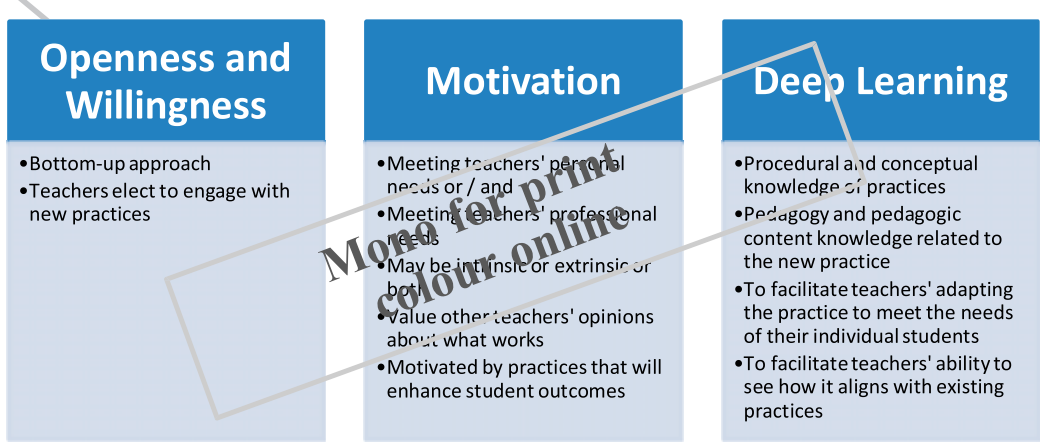

Figure 4. Teacher agency. 
implementation and survival over time. Principals also acknowledged this and therefore teachers were not mandated to engage with this practice. 'You're not going anywhere by cracking the whip on anything like this' (School principal). Teachers were unequivocal in outlining their motivation to engage with the literacy initiative centred on it being aligned with their personal and or professional needs at that time. This is in concert with Morgan et al. (2009) who argue that teachers are more concerned with what happens in their classroom that what is happening at school or national level. Additionally they are more interested in practices that they think will result in improved student outcomes than what others want teachers to do (Earley and Bubb 2004; Evans 2008). Getting the balance right between facilitating teacher autonomy and mandating practices to enhance school improvement can be challenging. Current orthodoxy suggests that no one size fits all and teachers in this study reflected that when they asserted that it was possible to adapt this literacy initiative to meet the individual needs of their students in their individual contexts. Arguably operating at such a critical level of practice (King 2014) reflects the concept of teachers having deep learning in relation to practices (Baker et al. 2004). This includes teachers understanding the pedagogy and having pedagogic content knowledge (PCK) related to the practice, that is having 'knowledge of ways of representing specific subject matter for pupils and an understanding of the difficulties they may face because of their existing conceptions' (Smith 2007, 378). Findings from this study showed evidence of many teachers engaging with the practice at this critical level (King 2013). While the literacy initiative stipulated that pupils read for three minutes each, one teacher felt it was not working for her students:

I felt three minutes was far too long for the tutee to concentrate, so I have changed it, tweaked it slightly ... they read four pages each. ... I'm constantly thinking of ways to make it better for them.

Another example includes a teacher, having critically observed the impact of working in mixed ability pairs changed this to having the top two pupils in the class work together in a same ability pairing to maximise their learning. Meanwhile another teacher added a more detailed comprehension dimension for pupils whose reading accuracy and fluency was already very good.

What works in one context and with some students may not work with others and teachers need to understand the pedagogy and the students in order to make informed decisions as reflected by another class teacher:

You have to manoeuvre out of a thing as structured as it is if they [students] are not getting this, this way, then you have to move that way.

This also shows that teachers are moving from what Shawer (2010) terms curriculum transmission towards curriculum development (teachers supplementing and adapting curriculum to local settings and needs) and curriculum making (teachers constructing curriculum having assessed individual students' needs). Sustainability of practices is more feasible if they can be individualised to meet the individual learning needs of students (Baker et al. 2004; Boardman et al. 2005). Underpinning all of this is teacher agency, that is, teachers acting in intentional ways to 'shape their own responses to problematic situations' (Fallon and Barnett 2009, 12). This study demonstrated that when teachers elected to engage in a literacy initiative to meet the needs of their students what eventuated was a PD multiplier which extended beyond sustainability of the new practices, it resulted in diffusion of 


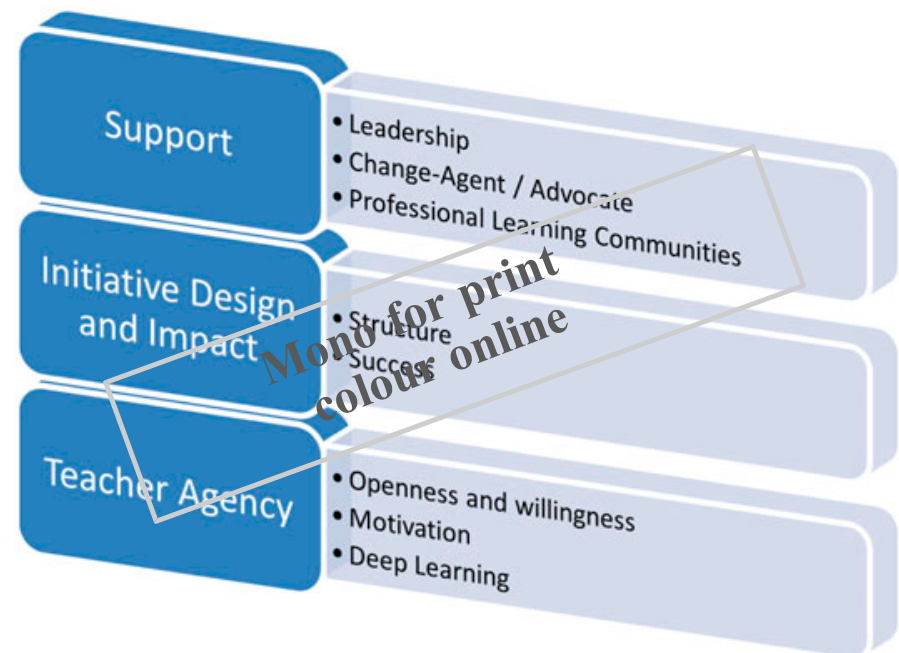

Figure 5. Systemic Factors to support teacher change.

practices to others, changes in teachers' beliefs, attitudes and values, engagement with other collaborative practices and changes at a cultural level (King 2014).

This paper focused on exploring factors that supported the implementation and sustainability of new practices over time. Findings have indicated that teaching and learning is a complex and contextual process influenced by a myriad of factors at play at any one given time; most notably those around Support, Initiative design and Impact and Teacher Agency. See Figure 5. While understanding the supporting features for implementation and sustainability of practices is important, arguably teachers and principals need to consider these when planning and evaluating the impact of their PD.

\section{Implications}

While the focus of this paper is on the Systemic Factors that supported the implementation and sustainability of change following teacher PD, implicit in the findings

15 is the issue of how teachers' PD is conceptualised and addressed as this seems to influence whether or not changes are implemented and sustained. It also reflects Kennedy's (2014) point of focusing on the purpose of PD. If PD is conceptualised as a third-order activity (Cordingley, Bell, and Thomason 2008) with an emphasis on changing teachers' practices (behaviours, knowledge, skills, understanding, val20 ues, attitudes or beliefs) to enhance student learning, then embedding the Systemic Factors into the planning and evaluation of PD to support the complex process of teacher professional learning needs to be considered. The three consistent features of Support, Initiative Design and Impact along with Teacher Agency may help towards understanding the complex system of teacher professional learning which is made 25 up of individual teachers, their interactions, school level systems and interactions between teachers and school-level systems (Opfer and Pedder 2011b). They may also help towards theorising teacher professional learning in a bid to narrow the knowledge practice gap. It has been observed that planning PD with the outcomes 
1. Baseline

2. Degree and quality of change

3. Systemic Factors

4. Learning Outcomes

5. PD Experience

\begin{tabular}{|c|c|c|}
\hline \multicolumn{3}{|c|}{ Teacher Professional Development } \\
\hline Planning & Key Consideration & Prompt Question \\
\hline \multirow{2}{*}{ Baseline } & $\begin{array}{l}\text { Individual / School Self- } \\
\text { Evaluation }\end{array}$ & Where are we now? \\
\hline & Targets & What do we want to achieve? \\
\hline \multirow{4}{*}{$\begin{array}{l}\text { Degree } \\
\text { and } \\
\text { quality of } \\
\text { change }\end{array}$} & Student outcomes & $\begin{array}{l}\text { What will the students be able to do: } \\
\text { (cognitive, affective and/or psychomotor } \\
\text { levels)? }\end{array}$ \\
\hline & Organisational & $\begin{array}{l}\text { What products/processes will help to } \\
\text { achieve the outcomes e.g. policies, staff } \\
\text { meetings, time, resources... }\end{array}$ \\
\hline & Staff/Teachers' Practice & $\begin{array}{l}\text { What instructional nractices (evidence- } \\
\text { based) will nroduce the desired student } \\
\text { outconines? }\end{array}$ \\
\hline & Diffusion & $\begin{array}{l}\text { Howtcan we enable diffusion of the } \\
\text { pfortices to other teachers and students? }\end{array}$ \\
\hline \multirow{3}{*}{$\begin{array}{l}\text { Systemic } \\
\text { Factors }\end{array}$} & Support & $\begin{array}{l}\text { Whin support will teachers need to } \\
\text { enhance teacher engagement e.g. } \\
\text { leadership support, internal/external } \\
\text { advocates, professional learning } \\
\text { community...? }\end{array}$ \\
\hline & Initiative Design and Impact & $\begin{array}{l}\text { Is the PD design structured and research } \\
\text { based, feasible and focused? Consider } \\
\text { factors of high quality CPD: duration, } \\
\text { collaborative, time-bound... } \\
\text { Is it evidence-based (producing successful } \\
\text { outcomes for students)? }\end{array}$ \\
\hline & Teacher Agency & $\begin{array}{l}\text { Are the teachers open, willing and } \\
\text { motivated to engage with change / a new } \\
\text { practice? Does it meet their personal or } \\
\text { professional needs? Are there } \\
\text { opportunities to facilitate teachers' } \\
\text { pedagogic and pedagogic-content- } \\
\text { knowledge development? }\end{array}$ \\
\hline $\begin{array}{l}\text { Learning } \\
\text { Outcomes }\end{array}$ & Teachers' Practice & $\begin{array}{l}\text { What knowledge, skills, attitudes will be } \\
\text { needed to implement changes? }\end{array}$ \\
\hline $\begin{array}{c}\text { PD } \\
\text { Experience }\end{array}$ & Activities/Experiences/Model & $\begin{array}{l}\text { What activities/training/model of } \\
\text { professional development do teachers need } \\
\text { to gain the required knowledge or skills? } \\
\text { Does the model match the purpose? }\end{array}$ \\
\hline
\end{tabular}

Figure 6. Framework for planning PD, 1 - Baseline, 2 - Degree and quality of change, 3 Systemic Factors, 4 - Learning Outcomes, 5 - PD Experience. 
in mind leads to better outcomes (Bubb and Earley 2010). Despite this, planning and evaluation of teacher PD by schools remains problematic and has been described as the weakest link in the PD chain (Ofsted 2006).

This paper argues that incorporating these Systemic Factors into a PD framework for planning teacher PD may help schools in this regard. This article presents an evidence-based PD planning framework (King 2014) which acknowledges the Systemic

10 Factors and can be used by teachers and schools for planning PD (Figure 6). It is hoped that using this framework will help bridge the gap between teacher PD and implementation and sustainability of new practices to result in improved student outcomes.

\section{Conclusion}

15 While numerous innovations have been introduced into schools, many have disappeared without a trace (Cuban 1988). The underlying difficulty seems to centre on implementation of new practices (Fullan 1999; Sahlberg 2012). Furthermore, little research exists on whether schools sustain the use of new practices that have been implemented despite this being central to long-term school improvement (Baker 20 et al. 2004; Priestley et al. 2011). This may be reflective of some studies showing that a number of teachers feel no responsibility to change practices as a result of PD (Bubb, Earley, and Hempel-Jorgensen 2008) which arguably relates to how PD is conceptualised. While some focus on PD for the purpose of transmission of knowledge and skills others may view it in a transformative manner where teachers are

25 supported to work collaboratively in a constructivist manner to change their practices to meet the needs of their students in their contexts (Kennedy 2005, 2014). Reconceptualising PD without restructuring does not result in lasting change (Grimmett 1995). Accepting that teacher PD is a right and a responsibility, planning and evaluating PD may help in reconceptualising and restructuring PD to lead to mean-

30 ingful change. However an understanding of how teachers learn and change practices is pivotal for realising meaningful change (Fullan 1991). This reflects an elemental ontological assumption that reality is subjective and constructed by the individuals who engage within it. Understanding the phenomenology of change aligns with an acknowledgement of human agency which sees teachers having the 35 capacity and the power to bring change despite the structures within which they operate. Therefore acknowledging the Systemic Factors, which include teacher agency, to support genuine change may help bridge the gap between teacher PD and enhanced student outcomes. It is acknowledged that these Systemic Factors need further rigorous testing in a variety of settings and using a range of methodological

40 studies. Nevertheless, it is hoped that they may contribute to the on-going debate of high quality and effective PD while at the same time contribute to theorising professional learning and reflect the complexity of the relationship between teacher $\mathrm{PD}$, professional learning, teacher engagement with change and enhanced student outcomes.

45 Disclosure statement 


\section{Notes on contributor}

Fiona King lectures in the School of Inclusive and Special Education, DCU Institute of Education, St. Patrick's Campus, Dublin City University. Her current research interests include teacher PD; social justice leadership, teacher leadership, special educational needs and inclusive teaching practices and, self-study as a research methodology.

\section{References}

Baker, S., R. Gersten. J.A. Dimino, and R. Griffiths. 2004. "The Sustained Use of ResearchBased Instruction (1) actice: A Case Study of Peer-assisted Learning Strategies in Mathematics." Remedidc und Special Education 25 (1): 5-24.

Bell, L., and R. Bolam. 2010. "Teacher Professionalism and Continuing Professional Development: Contested Concepts and Their Implications for School Leaders.' In The Principles of Educational Leadership and Management, edited by T. Bush, L. Bell, and D. Middlewood. 2nd ed. Los Angeles, CA: Sage.

Billett, S. 2009. "Conceptualizing Learning Experiences: Contributions and Mediations of the Social, Personal, and Brute." Mind, Culture and Activity 16 (1): 32-47.

Bjorkman, C., A. Olofsson. 2009. "Descriptions of Pre-conditions for Capacity-building in Schools." International Studies in Educational Administration 37 (2): 25-40.

Boardman, A.G., M. E. Arguelles, S. Vaughn, M. T. Hughes, and J. Klingner. 2005. "Special Education Teachers' Views of Research-based Practices." The Journal of Special Education, 39 (3): 168.

Bolam, R., A. Mch@in, L. Stoll, S. Thomas, M. Wallace, A. Greenwood, K. Hawkey, M. Ingram, A. Atkmon, and M. Smith/2005. Creating and Sustaining Effective Professional Learning Communities. Nottingham: Dfes Publications (Report number: RB637).

Bolt, S. 2007. "The Challenge of Integrating Research, Action and Learning in the Workplace to Affect Organisational Change." International Journal of Pedagogies and Learning 3 (2): 42-51.

Bryk, A. S., and B. Schneider. 2002. Trust in Schools. New York: Russell Sage.

Bryman, A. 2004. Social Research Methods. 2nd ed. Oxford: Oxford University Press.

Bubb, S., and P. Earley. 2008. From Self-evaluation to School Improvement: The Importance of Effective Staff Development. Institute of Education, University of London: CfBT Education Trust (Report number: PMS 4057 07/08).

Bubb, S., and P. Earley. 2010. Helping Staff Develop in Schools. London: Sage.

Bubb, S., P. Earley, and A. Hempel-Jorgensen. 2008. Staff Development Outcomes Study. London: Institute of Education.

Butler, F. M. 1999. "Reading Partners: Students Can Help Each Other Learn to Read." Education and Treatment of Children 22 (4): 415.

Carter, M., and K. Wheldall. 2008. "Why Can't a Teacher Be More like a Scientist? Science, Pseudoscience and the Art of Teaching." Australasian Journal of Special Education 32 (1): $5-21$.

Cordingley, P., M. Bell, B. Rundell, and D. Evans. 2004. The Impact of Collaborative CPD on Classroom Teaching and Learning. Institute of Education London: EPPI-Centre, Social Science Research Unit.

Cordingley, P., M. Bell, S. Thomason, and the Centre for the Use of Research and Evidence in Education (CUREE). 2008. Continuing Professional Development (CPD): The Evidence Base. London: Training and Development Agency for Schools.

Cuban, L. 1988. "Constancy and Change in Schools (1880s to the Present)." In Contributing to Educational Change: Perspectives on Policy and Practice, edited by, P. W. Jackson, 85-104. Berkeley, CA: McCutchan.

Desimone, L., A. C. Porter, M. S. Garet, K. S. Yoon, and B. F. Birman. 2002. "Effects of Professional Development on Teachers' Instruction: Results from a Three-Year Longitudinal Study." Educational Evaluation and Policy Analysis 24 (2): 81-112.

Earley, P., and S. Bubb. 2004. Leading and Managing Continuing Professional Development. London: Sage.

Eivers, E., A. Clerkin, eds. 2013. National Schools, International Contexts: Beyond the PIRLS and TIMSS Test Results. Dublin: Educational Research Centre. 
Evans, L. 2008. "Professionalism, Professionality and the Development of Education Professionals." British Journal of Educational Studies 56 (1): 20-38.

Evans, L. 2010. "Leadership for Faculty Development: Confronting the Complexity of Professional Development." Paper presented at American Educational Research Association, Denver, Colorado, USA, May 3.

Fallon, G., and J. Barnett. 2009. "When is a Learning Community Just a Pseudo Community? Towards the Development of a Notion of an Authentic Learning Community." International Studies in Educational Administration 37 (2): 3-24.

10 Fullan, M. 1999. Change Forces: The Sequel. Philadelphia, PA: Falmer Press.

Fullan, M. 2001. The New Meaning of Educational Change. 3rd ed. New York: Teachers College Press.

Fullan, M. 1991. The New Meaning of Educational Change. New York: Teachers College Press.

Fullan, M., C. Cuttress, and A. Kilcher. 2005. "8 Forees for Leaders of Change." Joutnat of Staff Development 26 (5): 5464.

Garet, M. S., A. C. Porter, L. Desimone, B. F. Birman, and K. S. Yoon. 2001. "What Makes Professional Development Effective? Results from a National Sample of Teachers." American Educational Research Journal 38 (4): 915-945.

Gewirtz, S., and S. Ball. 2000. "From 'Welfarism' to 'New Managerialism': Shifting Discourses of School Headship in the Education Marketplace.’ Discourse 21 (3): 253-268.

Gray, D. E. 2004. Doing Research in the Real World. London: Sage.

Grimmett, P. 1995. "Reconceputalizing Teacher Education: Preparing Teachers for Revitalized Schools." In Changing times in Teacher Education: Restructing or Reconceptualization?, edited by M. Wideen and P. Grimmett. London: Falmer Press.

Guskey, T. R. 1991. "Enhancing the Effectiveness of Professional Development Programs." Journal of Educational and Psychological Consultation 2 (3): 239-247.

Guskey, T. R. 2002. "Does It Make a Difference?" Evaluating Professional Development. Educational Leadership 59 (6): 45-51.

30 Hall, G., and S. Hord. 2006. Implementing Change: Patterns, Principles and Potholes. Toronto: Pearson Education.

Hargreaves, A. 1994. Changing Teachers, Changing times: Teachers' Work and Culture in the Postmodern Age. New York: Teachers College Press.

Hargreaves, A., and M. Fullan. 1992. Teacher Development and Educational Change. Basingstoke: Falmer.

Hattie, J. 2003. "Teachers Make a Difference: What is the Research Evidence?" Paper presented at Australian Council for Educational Research Annual Conference on Building Teacher Quality, Melbourne, October 21-23.

Hayton, P., and J. Spillane. 2008. Professional Community or Communities? School Subject Matter and Elementary School Teachers' Work Environments. In Leadership for Learning. International Perspectives, edited by. J. MacBeath and Y. C. Chen, 59-71. Rotterdam: Sense.

Joyce, B., and B. Showers. 1995. Student Achievement through Staff Development. 2nd ed. New York: Longman.

45 Kennedy, A. 2005. "Models of Continuing Professional Development: A Framework for Analysis." Journal of in-Service Education 31 (2): 235-250.

Kennedy, A. 2011. "Collaborative Continuing Professional Development (CPD) for Teachers in Scotland: Aspirations, Opportunities and Barriers." European Journal of Teacher Education 34 (1): 25-41.

50 Kennedy, A. 2014. "Understanding Continuing Professional Development: The Need for Theory to Impact on Policy and Practice." Professional Development in Education 40 (5): 688-697.

Kervin, L. 2007. "Supporting Elementary Teachers at the 'Chalk-Face': A Model for InSchool Professional Development." International Electronic Journal for Leadership in Learning, 11 (10) [Online]. Accessed February 26, 2016. http://files.eric.ed.gov/fulltext/ EJ987308.pdf

King, F. 2012. "Developing and Sustaining Teachers' Professional Learning: A Case Study of Collaborative Professional Development." Unpublished EdD Thesis, University of 
Lincoln, Lincoln, England. Accessed May 2, 2014. http://eprints.lincoln.ac.uk/6805/1/The sis - Dr Fiona King 2012.pdf

King, $\bar{F} . \overline{2}$ 2013. "Leading the Way to Bridge the Gap between Teacher Professional Development and Student Outcomes." Paper presented at annual conference of the British Educational and Leadership, Management and Administration Society (BELMAS), Dalmahoy, Edinburgh, July 12-14.

King, F. 2014. "Evaluating the Impact of Teacher Professional Development: An EvidenceBased Framework." Professional Development in Education 40 (1): 89-111.

Knowles, M. S. 1980. The Modern Practice of Adult Education: From Pedagogy to Andragogy. New York: Cambridge Adult Education.

Miles, M. B., and A. M. Huberman. 1994. Qualitative Data Analysis: An Expanded Sourcebook. 2nd ed. Thousand Oaks, CA: Sage.

Morgan, M., L. Ludlow, K. Kitching, M. O’Leary, and A. Clarke. 2009. "What Makes Teachers Tick? Sustaining Events in New Teachers' Lives.' British Educational Research Journal 36 (2): 191-208.

NCCA (National Council for Curriculum and Assessment). 2008 Primary Curriculum Review, Phase 2: Final Report with Recommendations. Accessed January 31, 2011. http://www.ncca.ie/en/Publications/Reports/Primary Curriculum Review, Phase_2_Final_report_with_recommendations,pdf

NCC̄A (National Council for Curriculum and Assessment). 2010 Leading and Supporting Change in Schools: Discussion Paper. Accessed January 31, 2011. http://ncca.ie/en/Abou t_Us/Strategic_Plan/leading_and_supporting_change.pdf

New South Wales (NSW) Institute of Teachers. 2007. Continuing Professional Development Policy. Accessed November 24, 2008. http://www.nswteachers.nsw.edu.au/

Norris, N. D. 2004. "Staff Development: Creating a Community of Learners." International Electronic Journal for Leadership in Learning 8 (2). Accessed January 12, 2009. http:// iejll.journalhosting.ucalgary.ca/index.php/ijll/article/view/695/355

O’Sullivan, H. 2011. "Leading and Managing Professional Learning in Schools." In Leading and Managing Schools, edited by. H. O'Sullivan and J. West-Burnham., 111-125. London: Sage.

(Ofsted) Office for Standards in Education. 2006. The Logical Chain. London: Ofsted.

Opfer, V. D., and D. Pedder. 2011a. "The Lost Promise of Teacher Professional Development in England." European Journal of Teacher Education 34 (1): 3-24.

Opfer, V. D., and D. Pedder. 2011b. "Conceptualizing Teacher Professional Learning." Review of Educational Research 81: 376-407.

Opfer, V. D., D. Pedder, and Z. Lavicza. 2010. The Role of Teachers' Orientation to Learning in Professional Development and Change: A National Study of Teachers in England. Teaching and Teacher Education, doi:10.1016/j.tate.2010.09.014. http://www.dar leenopfer.com/File/TATE1506 proof.pdf.

Priestley, M., K. Miller, L. Barrett, and C. Wallace. 2011. "Teacher Learning Communities and Educational Change in Scotland: The Highland Experience." British Educational Research Journal 37 (2): 265-284.

Sahlberg, P. 2012. How Can Research Help Educational Change?

Seed, A. H. 2008. "Redirecting the Teaching Profession in the Wake of a Nation at Risk and NCLB." Phi Delta Kappan 89 (8): 586-589.

Sergiovanni, T. 2005. Strengthening the Teaching Professional in the Wake of a Nation at Risk and NCLB. San Francisco, CA: Jossey Bass.

Shawer, S. 2010. "Classroom-Level Teacher Professional Development and Satisfaction: Teachers Learn in the Context of Classroom-Level Curriculum Development." Professional Development in Education 36 (4): 597-620.

Smith, R. G. 2007. "Teachers \& Teaching. Developing Professional Identities and Knowledge." Becoming Primary Teachers 13 (4): 377-397.

Stoll, L., and D. Fink. 1996. Changing Our Schools: Linking School Effectiveness and School Improvement. Maidenhead: Open University Press.

Sytsma, S. 2006. "Mentoring: The Journey of Eyes." International Electronic Journal for Leadership in Learning 10 (12).

(TCI) Teaching Council of Ireland. 2011. Policy on the Continuum of Teacher Education. Maynooth: Teaching Council of Ireland. 
Timperley, H. 2008. Teacher Professional Learning and Development. Brussels: International Academy of Education (IAE).

Topping, K. 1988. The Peer Tutoring Handbook. London: Croom Helm.

Wermke, W. 2010. "Continuing Professional Development in Context: Teachers' Continuing Professional Development Culture in Germany and Sweden." Professional Development in Education 37 (5): 665-683.

\section{Appendix A. A 30 min Peer Tutoring Session generally includes}

- Giving out the folders

- Recapping on previously read piece or in the case of a new book discussing the title, illustrations, what the book may be about as per the bookmark (2-3 min).

- Reader $1 /$ Tutor reading from wherever the tutee left off previously $(5 \mathrm{~min})$.

- Reader 2/Tutee reading with tutor supporting and recording unknown words on Unknown Words Recording Sheet (5 min).

- Sight Word Practice (15 min):

$\circ$ any newly recorded words are looked up in the dictionary where meaning is unknown

$\circ$ a flash card is made of any newly recorded words

$\circ$ newly recorded words are practised and put orally into sentences

$\circ$ newly recorded words are put into the tutee's/tutor's personalised dictionary and put into a written sentence in the personalised dictionary to support memory of the word

$\circ$ previous sight word flashcards in the green pocket i.e. with 1 or 2 circles on them are revised for recognition, pronunciation, meaning, putting into oral sentences, counting syllables etc.

o tutee is asked to recognise all flashcards and a circle is added where words are recognised, pronounced correctly and meaning is known

- flashcards with 3 accumulated circles are placed in the red pocket, flashcards with 1 or 2 circles remain in the green pocket

- Folders are tidied up and books are changed where necessary.

Note: On Day 4 the Sight Word Practice is divided between the main folder (with the pockets) initially and then the flashcards in the expandable folders. Any flashcards in the red pockets of the main folders are transferred to the expandable folder and then all flashcards in this folder are practiced. 